\title{
Exploring Residential Heterogeneity through Multiscalar Lens: A Case Study of Hangzhou, China
}

\author{
Qinshi Huang $\mathbb{D D}^{1,2}$ Weixuan Song $\mathbb{D D}^{3}{ }^{3}$ Liyan Liu, ${ }^{4}$ Chunhui Liu, ${ }^{5}$ Xinyi Zhang, ${ }^{1}$ and Ge He \\ ${ }^{1}$ School of Architecture and Urban Planning, Nanjing University, Nanjing 210093, China \\ ${ }^{2}$ School of Civil Engineering and Architecture, Zhejiang University of Science and Technology, Hangzhou 310023, China \\ ${ }^{3}$ Key Laboratory of Watershed Geographic Sciences, Nanjing Institute of Geography and Limnology, Chinese Academy of Sciences, \\ Nanjing 210008, China \\ ${ }^{4}$ State Key Laboratory of HPC \& SIP (MOE of China) and College of Mathematics and Statistics, Hunan Normal University, \\ Changsha 410081, China \\ ${ }^{5}$ College of Humanities and Social Development, Nanjing Agricultural University, Nanjing 210095, China
}

Correspondence should be addressed to Weixuan Song; wxsong@niglas.ac.cn

Received 31 July 2020; Revised 26 October 2020; Accepted 21 January 2021; Published 23 February 2021

Academic Editor: Jun Yang

Copyright (C) 2021 Qinshi Huang et al. This is an open access article distributed under the Creative Commons Attribution License, which permits unrestricted use, distribution, and reproduction in any medium, provided the original work is properly cited.

\begin{abstract}
The pattern, process, and mechanism of residential heterogeneity vary significantly with different geographical scales. However, most traditional methods ignore the checkboard and modifiable areal unit problem (MAUP), which may cover up the complexity and hierarchy of social space. Taking Hangzhou city as an example, a multiscalar method was proposed based on the information entropy theory to estimate residential heterogeneity and its scale sensitivity. Based on the sixth population census of Hangzhou and the housing price database of 6,536 residential districts from 2008 to 2018, we explore the scale effect and dynamic characteristics of residential heterogeneity. The results of spatial simulation and geostatistical analysis based on Python Spatial Analysis Library (PySAL) module show that the multiscalar algorithm better presents the real segregation pattern than traditional method, which is one of the new models and technologies in urban geography complex system. Exploring residential heterogeneity through multiscalar lens provides an important basis for the gradual and refined urban renewal.
\end{abstract}

\section{Introduction}

In the context of neoliberalism and capitalism, the complexity of urban residential geography becomes more pronounced as its diversity increases. The sociospatial differentiation dominantly represented by residential heterogeneity is one of the effective ways to identify periphery and vulnerable area. While physical geography and remote sensing have always placed the concept and rescaling of scale at the forefront of their research, including cartographic scale, geographic scale, operational scale, and measurement scale [1], human geography, on the other hand, paid little attention to the scale problem and has different theories and methodologies [2], with three main sociological implications [3]. Firstly, scale refers to the spatial categories or geographic scope we use to understand and study our world, including the global, nation, local, households, and everyday life [4]. Secondly, scale is used to represent the level of social practices and spatial structure [5]. In addition, based on the theory of scale politics, scale is also a component of space production and the crystallization of social relations [6]. From the classical factorial ecology of Chicago School to the radical Marxism and positivism in the 1970s [7, 8] and to the recent paradigms of spatial simulation and geostatistics, human geographer has systematically studied the heterogeneity of social area for nearly a century and called for a more complex and multidimensional methodologies $[9,10]$. The quantitative study on the heterogeneity of residential space can also be used to evaluate the spatial efficiency of urban policy initiatives, thus providing a basis for analysis and public policy intervention [11]. Indeed, the spatial lens through which we measure segregation has a profound effect 
on more just and socially equitable public policies, community development, and responsible governance [12].

Residential heterogeneity reflects the geographic unevenness of social resource in urban space, presenting a mosaic landscape full of diversity and polarization overlapping [13]. Scholars have struggled to adjust indicators of social segregation to measure residential segregation in the context of more complex, multiracial, and marginalized realities [14]. Since Duncan came up with the earliest Dissimilarity Index (D) in 1955 [15], more than 20 types of indices have been developed. Earlier indices, such as the classic Gini Index (G) [16], Atkinson Index (A) [17], and Information entropy Index $(\mathrm{H})$ [18], were essentially global nonspatial indices that did not take into account spatial proximity and geographical scale, which may be sensitive to the variations in the number and population of tracts [19]. In the 1980s, the comparison of different indices stimulated a wave of reflection on the methodology of dissimilarity index. The second-generation differentiation index, represented by Exposure Index (xPy), improved the index by considering the spatial distribution of different groups based on the distance decay function [20]. At the end of the 20th century, rapid urban expansion and suburbanization that resulted in the global residential heterogeneity in macroscale seems to be less significant [21]. If we still use a single-scalar index, this may produce segregation paradox [22, 23]. That is, although the segregation index seems to be decreasing, the real segregation and contradiction within the space is still increasing. The third-generation index, represented by Spatial Dissimilarity Index (SDI), is modified by adding spatial weight matrix $[24,25]$. Generally, the research of residential heterogeneity has changed from single-scalar paradigm to macro-micro research or macro refinement method. Multiscalar lens provides a framework to integrate the macrostability and microdiversity of urban complex systems [26].

The multiscalar phenomenon of residential differentiation was discovered as early as the mid-20th century $[27,28]$. That is, residential heterogeneity is higher on a smaller scale and lower on a larger scale, also known as the modifiable areal unit problem (MAUP) [29]. However, due to technical and data constraints, this issue did not attract the attention of the economic geography at that time. The multiscalar analysis techniques for spatial heterogeneity have only recently been implemented and become the cutting edge of research [30]. In order to overcome the checkboard problem and modifiable areal unit problem (MAUP), Wong proposed a boundary modified version dissimilarity index based on the ratio of perimeter to area [31]. Reardon argued that scale sensitivity could be reduced by analyzing the spatial segregation profiles and the macro-micro segregation ratio [32]. O'sullivan and Wong attempt to simulate spatial segregation and its scale effects using a kernel density estimation method [33]. Fowler further demonstrates the key assumptions for multiscalar segregation measures [34]. Manley uses a multiscalar method to modeling the macro-, meso-, and microscale residential patterns in Auckland, New Zealand, from 2001 to 2013 [35]. Johnston and other scholars have creatively proposed a dissimilarity model which considers both macrostability and microdiversity [36]. Hennerdal and Nielsen developed a multiscalar method based on $k$-nearest neighbors to measure the exposure for different ethnic groups [37]. Similarly, Catney used a spatial weighting method to test the scale effect in England and Wales [12]. Recent work on modeling residential heterogeneity tends to shift from traditional environmental or economic determinism in framing multidimensional lenses and problem-oriented paradigm.

Previous studies mainly measure the residential heterogeneity by aggregating predefined census tracts, which is difficult to overcome the data randomness and MAUP. With the advent of fine-grained and massive data, it is possible to quantitatively study the multiscalar phenomenon between and within different spatial units. In view of these identifiable gaps and the opportunities provided by multiscalar measures, three core themes are explored. Primarily, this paper proposes a novel methodology for evaluating algorithms that calculate social influence in residential heterogeneity. Secondly, this paper systematically studies the relationship between different dimensions of residential differentiation and provides data support and theoretical basis for differential urban renewal measures and progressive refined spatial restoration. Thirdly, it also contributed to the interpretation of changing segregation patterns in response to the complex interaction of a variety of structures and developments on different spatial levels. The paper is structured as follows. The next section presents the social reproduction of geographic scale. The third section presents study area, data processing, and the methodological aspects of multiscalar segregation. The fourth section presents the results of the estimated empirical model for residential heterogeneity. The fifth section presents the conclusion and provides a discussion.

\section{The Reproduction of Geographic Scales}

Geographic scales are produced rather than given, which is defined as the reproduction of labor and the journey of work [38]. The reproduction of geographic scales explores how residents themselves shape the constitution of these scales in complex ways, including a dual structure of regional scope and relational hierarchy [39]. Different resources and social structures provide different investment returns for different investments. At the same time, competition between different regions to attract capital exacerbates geographical imbalances. With the restructuring of labour-capital relations and subsequent reassembly, the unevenness of resources allocation and development in urban social morphologies, infrastructures, and everyday life are becoming more fragmented and diversified [40]. The theory of social reproduction of geographical scale is derived from the Marxist theory of space economy, the political economy. Since Smith had introduced the concept of politics of scale, Radical Marxist scholars have emphasized how economic and political processes shape the emergence of scales [41]. For Brenner, geographic scales can be understood through the hierarchization and rehierarchization among vertically differentiated spatial units [6]. Studies have shown that a decline of dissimilarity index in one scale or single 
dimension does not necessarily imply an increase of social integration or mobility. As Smith and Dennis argue, US society in the 1970s was likely to shift from regional to more localized unevenness, and multidimensional approach helps to depict a more complex view of complex reality [42].

Capital accumulation and circulation are the main driving force of urban development, and what kind of leverage to achieve the "scale jump" is a difficult task. Scale reconstruction leads to the change of the weight of local spatial units in the global landscape, and the corresponding spatial power and governance results are also reshaped [43]. Smith's idea of nested scales emphasizes the interdependence of these processes [38]. Harvey further emphasized that labor surplus and capital surplus can be recycled through scale reconstruction and reproduction to achieve spatial fix [44]. The government-oriented scalar reconstruction tries to reduce the regional disparity by investing in technology and social expenditures. On the other hand, the capital-oriented scalar reproduction improves the efficiency of capital flow through consumption fund and fixed capital. Based on the spatial fix theory, this paper proposes an analytical framework for the reproduction of geographic scales (see Figure 1). The theory of scale politics makes the study of residential heterogeneity turn from flat to structural scale and from unitary to pluralistic scale. However, previous studies are mostly based on national or census scale. This paper exploring residential heterogeneity and its dynamic mechanism through multiscalar perspective provides an important basis for the gradual and refined urban renewal.

\section{Materials and Methods}

3.1. Study Area. Hangzhou is an important central city of the Yangtze River Delta and a transportation hub in southeastern China and a pioneer in the transformation of the urban service industry and information technology. From 1990 to 2018, the urban built-up area increased from 69 to $615 \mathrm{~km}^{2}$, and the urban scale expanded nearly 10 times. The land expansion of urban built-up area mainly comes from the continuous increase of agricultural land in urban fringe area during the process of administrative territorial entity adjustment. Urban expansion has resulted in a large number of land-lost farmers and migrants living in informal settlements, which makes Hangzhou a typical case to study residential heterogeneity. The study mainly covers the whole urban area of Hangzhou, including the eight districts of Shangcheng, Xiacheng, Xihu, Gongshu, Jianggan, Binjiang, Xiaoshan, and Yuhang, not including Fuyang and Lin'an districts, which were newly established administrative district from cities in these years (see Figure 2).

The data are mainly extracted from the sixth national census, and based on the Chinese house price platform (http://www. creprice.cn), the whole sample housing transaction data of 6,536 residential districts in Hangzhou from 2008 to 2018 are obtained. Census data include the sociodemographic characteristics of all individuals, such as sex, age, race, and education, which are comprehensive but time-lagged. Housing price reflects the unbalanced allocation of residential resources and housing demands, which to some extent overcome the shortage of the time lag. Therefore, we adopt the method of combining population census with housing data and take Hangzhou City as an example to set up a research framework of spatial differentiation on three scales of population census, block, and grid; the heterogeneity of residential space in different population and scale was studied by using spatial information entropy and scalesensitive profiles.

3.2. The Dimension and Methodology. The dimension and methodology of segregation adopted in this study follows that of Reardon and O'Sullivan [45]. For a long time, scholars have been debating about the different dimensions [14] and measurements [46] in which residential heterogeneity can be conceptualized. Massey and Denton firstly proposed five dimensions of segregation, including unevenness, exposure, concentration, centralization, and clustering. While Reardon proposes that there is overlap between these classic five dimensions and further generalizes them into two dimensions, including evenness and exposure. Here, we use the information entropy index $(H)$ and spatial information entropy index $(\widetilde{H})$, combining with exposure isolation index $(x P x)$ and spatial exposure isolation index $(x \widetilde{P} x)$, to assess the residential heterogeneity in both nonspatial and spatial versions.

The information entropy index $(H)$ is considered to be the most effective index to measure the geographical evenness, which refers to the extent to which groups are similarly distributed in residential space. A disorganized complexity system can be defined as an entropy function [47]. Then, we constructed the information entropy index $(H)$ of residential heterogeneity based on Theil's information entropy index:

$$
\begin{gathered}
H=\sum_{i=1}^{I} \frac{N_{i}\left(E-E_{i}\right)}{E N}, \\
E=\sum_{j=1}^{J}\left(n_{j}\right) \ln \left(\frac{1}{n_{j}}\right), \\
E_{i}=\sum_{j=1}^{J}\left(n_{i j}\right) \ln \left(\frac{1}{n_{i j}}\right),
\end{gathered}
$$

where $E$ is the global entropy, $E_{i}$ is the entropy of spatial unit $i \in\{1, \ldots, I\}, N_{i j}$ is the population of group $j \in\{1, \ldots, J\}$ at spatial unit $i \in\{1, \ldots, I\}$, and $n_{i j}$ is the proportion of group $j \in\{1, \ldots, J\}$ at spatial unit $i \in\{1, \ldots, I\}$. And isolation $(x P x)$ assesses how much a minority group is only exposed to the same group, in other words how much they only interact with the members of the group they belong to. This paper uses Bell's isolation index $(x P x)$ to measure exposure to residential heterogeneity in exposure dimension:

$$
x P x=\sum_{i=1}^{I}\left(\frac{N_{i x}^{2}}{N_{i} N_{x}}\right) .
$$

Unless spatial subarea boundaries correspond to meaningful social boundaries, all measures of segregation that rely on population counts aggregated within subareas 


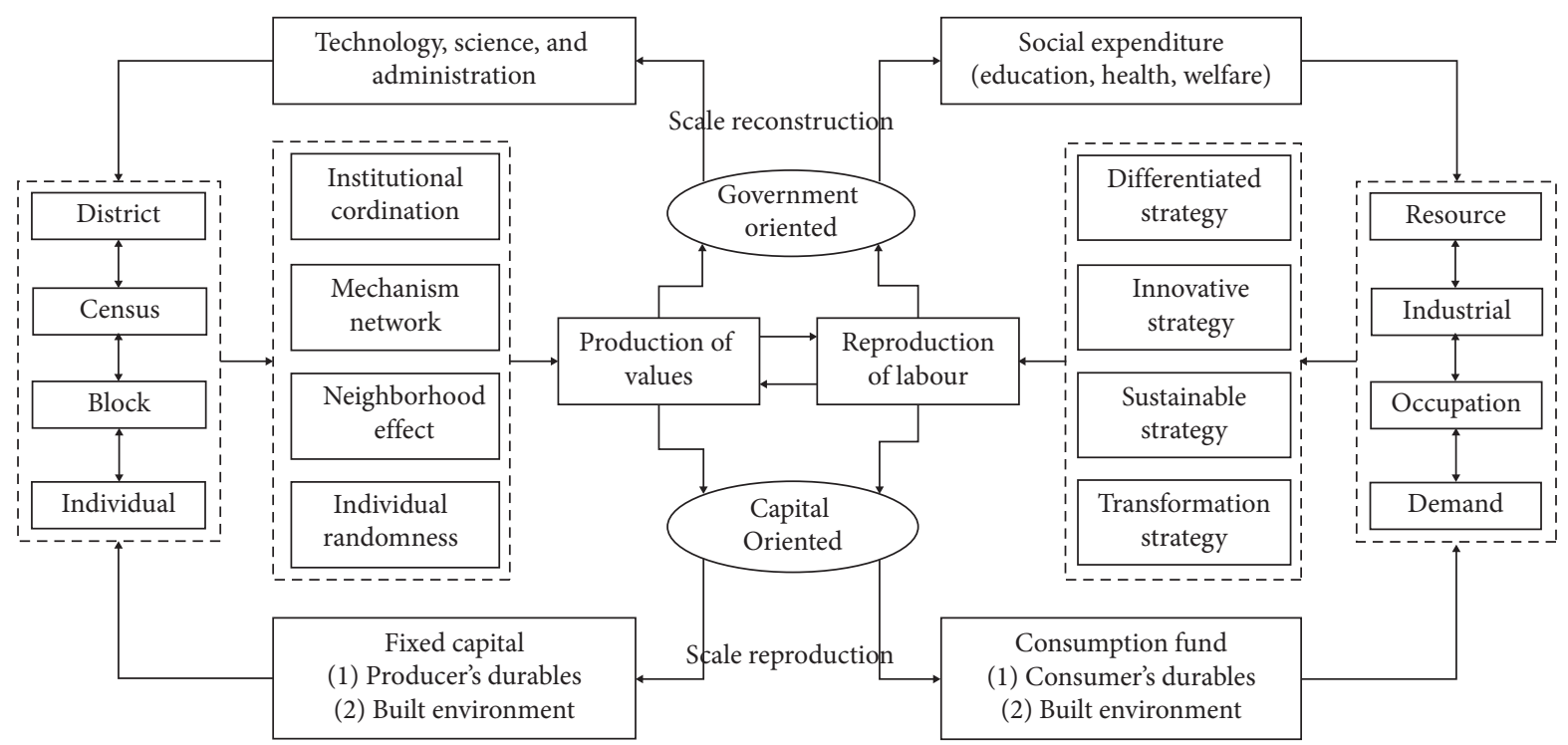

FIGURE 1: The capital circulation of the geographic scales' reconstruction and reproduction.

are sensitive to the definitions of the boundaries of these spatial subareas. Based on local segregation index $\left(L_{i j}\right)$ developed by Feitosa, we adopted a kernel-based spatial weighted index to improve the aspatial approach:

$$
\begin{aligned}
L_{i} & =\sum_{i=1}^{I} k\left(N_{i}\right), \\
L_{i j} & =\sum_{i=1}^{I} k\left(N_{i j}\right), \\
\tau_{i j} & =\frac{L_{i j}}{L_{i}}
\end{aligned}
$$

where $k$ is the kernel estimator which estimates the influence of each areal unit on the locality $i$. The local population intensity of locality $i\left(L_{i}\right)$ and the local population of group $j\left(L_{i j}\right)$ are computed using a kernel estimator placed on the centroid of areal unit $i$ and the weights are given by the choice of a distance decay function and parameter, and we also computed the local proportion of group $j$ in locality $i\left(\tau_{i j}\right)$. Based on the spatial proximity and the local environment, we compute the spatially weighted information entropy $(\widetilde{H})$ at each unit $i$ :

$$
\begin{aligned}
& \widetilde{H}=\sum_{i=1}^{I} \frac{N_{i}\left(\widetilde{E}-\widetilde{E}_{i}\right)}{\widetilde{E} N}, \\
& \widetilde{E}=\sum_{j=1}^{J}\left(\tau_{j}\right) \ln \left(\frac{1}{\tau_{j}}\right), \\
& \widetilde{E}_{i}=\sum_{j=1}^{J}\left(\tau_{i j}\right) \ln \left(\frac{1}{\tau_{i j}}\right) .
\end{aligned}
$$

Likewise, based on the method of Morgan, we developed an integral version distance decay exposure $(x \widetilde{P} x)$ as follows:

$$
x \widetilde{P} x=\iint_{i_{1}, i_{2} \in I} \frac{N_{i_{1 x}}^{2}}{N_{x} N_{i_{1}}} P_{i_{1} i_{2}} d i_{1} d i_{2}, P_{i_{1} i_{2}}=\frac{\exp \left(-d_{i_{1} i_{2}}\right) N_{i_{2}}}{\sum_{i_{2}=1}^{I} \exp \left(-d_{i_{1} i_{2}}\right) N_{i_{2}}},
$$

where $a_{i}$ is the area of unit $i$ and $d_{i_{1} i_{2}}$ is a pairwise distance between area $i_{1}$ and $i_{2}$ and is estimated as $d_{i i}=\left(\alpha a_{i}\right)^{\beta}$. $P_{i_{1} i_{2}}$ could be seen as the probability of contact of members of group $x$ to each other weighted by the inverse of distance. The default is $\alpha=0.6$ and $\beta=0.5$. For the distance measure, we first extract the centroid of each unit and calculate the Euclidean distance.

3.3. Data Processing. In this study, the census-level data is pregiven in the 6th population census, and we preprocess the block-level and grid-level data as follows. Firstly, the study area is divided into 1155 block units surrounded based on the main roads and administrative boundary by using topology and feature to polygon tools in ArcGIS. Comparing remote sensing images, 887 block units were remained by eliminating uninhabited blocks. Secondly, the study area is divided into 3617 grid units by $1000 \mathrm{~m}$ Fishnet, and the nonnull grid units were remained by overlaying the whole grid unit as before. Finally, we estimate the population of different housing prices based on housing prices and home size and divide them into five groups through natural breaking points. The population of different housing prices is extracted to different level units by using the extract values to polygon tools in ArcGIS.

The spatial indices have theoretical advantages over the conventional ones but have been rarely used, primarily due to the computational difficulties. With the development of geostatistics models and techniques in the past decade, a number of methods try to improve the implementation of segregation model through GIS and R since 2014 [48, 49]. The advantages of open-source software of urban complex systems in the academic realm have become obvious. Python 


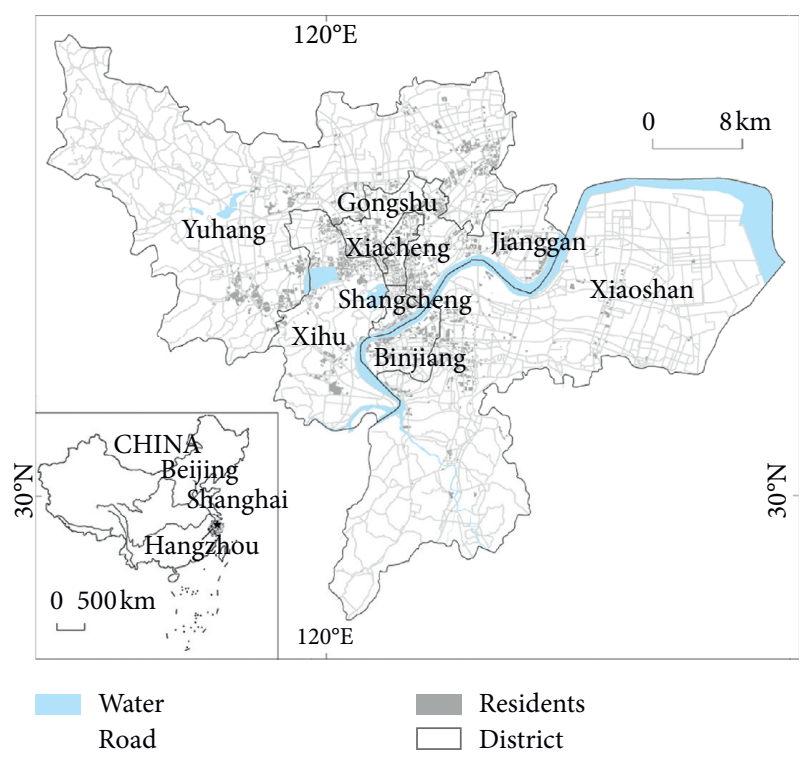

(a)

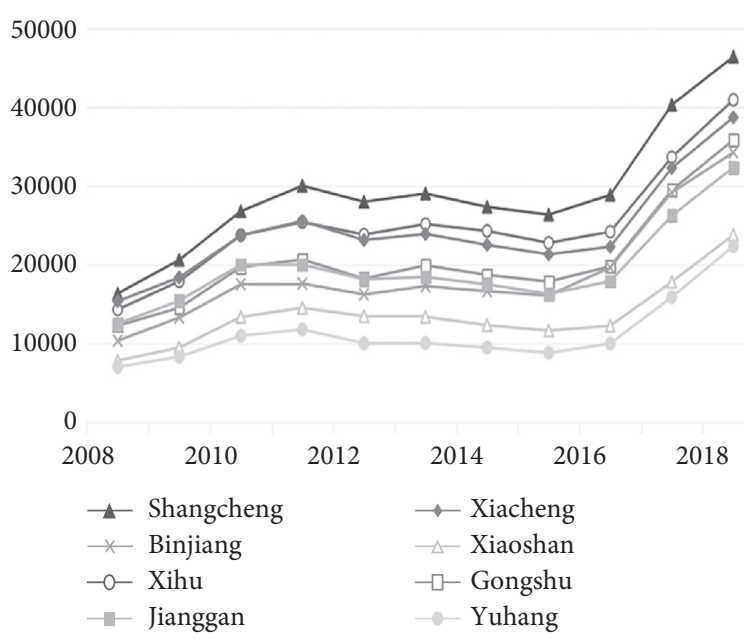

(b)

FIgURE 2: Study area and housing price distribution in Hangzhou. (a) Study area. (b) Housing price distribution $\left(\mathrm{Rmb} / \mathrm{m}^{2}\right)$.

Spatial Analysis Library (PySAL) is a comprehensive Python Library of spatial analysis, including spatial data analysis, spatial econometrics, geographic processing, and spatial data visualization function, which is the most effective way to study residential heterogeneity. Based on the open-source PySAL module developed by Cortes et al. [50], this paper explores residential heterogeneous through multiscalar lens based on spatial weight matrix and street network distance.

\section{Results and Discussion}

4.1. Residential Heterogeneity of Different Groups and Dimensions. The method of social area analysis based on census data has been a classic paradigm for the study of residential heterogeneity in the past century. Compared with the globalism and neoliberalism in Western countries, the structure and characteristics of residential heterogeneity in China have gradually changed from a planned economy to a market economy, which has experienced more intense and complex spatial reconstruction and social transformation. Among different groups and backgrounds, migrant, female, education, and occupation have the main factors to study the differentiation of traditional residential areas [51, 52]. While China's household registration system during the transition period is one of the unique social characteristic variables of residential heterogeneity in China's metropolitan, which to a large extent results in the separation of welfare treatment and social opportunity for the relevant groups, which greatly affects the segregation of welfare and opportunity of relevant groups. Therefore, besides classical social area analysis, we also add the household registration variable, called Hukou, to analyze the spatial pattern of residential heterogeneity in Hangzhou. According to relevant studies [53, 54], we analyzed the 9 groups in the study area, including migrant, female, hukou, agriculture and husbandry, professional and technical, business and services, highly educated (college degree or above), elderly (over 60), and unemployment based on census data.

From the dimension of evenness, nonspatial segregation degree of different population groups was the highest (0.21603), followed by agriculture and animal husbandry group (0.18064), higher education group (0.13846), and floating population (0.10730). The segregation degree of the female group is the lowest (0.00219), the professional and technical personnel (0.02431), the commercial and service personnel (0.02711), the unemployed group (0.01901), and the information entropy index of the elderly population $(0.05324)$ is also less than 0.1 . The results showed that the spatial distribution of different sex groups in Hangzhou was relatively uniform. In general, the nonspatial information entropy index based on census data is not significant on the whole, and the spatial distribution of census population is the most uneven; single-scale analysis will be drawn in 2010. Hangzhou social space has been more homogeneous spatial paradox (see Table 1 and Figure 3).

From the dimension of exposure, except the contact degree of agriculture and animal husbandry groups is less than the uniformity, the isolation of other groups in the contact dimension is higher than the uniformity. Among these groups, professional and technical workers were most exposed (0.71963), indicating a 71.963 percent probability in the life of the population engaged in professional and technical work to have contact with persons within their own group and a high degree of isolation from other groups; perhaps this has to do with the fact that most of the people concerned living mainly near their place of employment. Secondly, the isolation index (0.67199) of household population is higher, which shows that household population has very significant residential isolation in both evenness and exposure dimensions; it is one of the most important 
TABLe 1: Residential heterogeneity of different groups and dimensions in Hangzhou.

\begin{tabular}{|c|c|c|c|c|c|}
\hline & \multicolumn{3}{|c|}{ Evenness $(H)$} & \multicolumn{2}{|c|}{ Exposure $(x P x)$} \\
\hline & Aspatial & Spatial $(500 \mathrm{~m}$ bw $)$ & Spatial $(1000 \mathrm{~m}$ bw) & Aspatial & Spatial (decay) \\
\hline Migrant & 0.10730 & 0.07853 & 0.07370 & 0.52312 & 0.00183 \\
\hline Female & 0.00219 & 0.00159 & 0.00163 & 0.48744 & 0.00655 \\
\hline Hukou & 0.21603 & 0.21419 & 0.20585 & 0.67199 & 0.01852 \\
\hline Agriculture and husbandry & 0.18064 & 0.18931 & 0.17987 & 0.12330 & 0.00967 \\
\hline Professional and technical & 0.02431 & 0.02137 & 0.01985 & 0.71963 & 0.00739 \\
\hline Business and services & 0.02711 & 0.02148 & 0.02139 & 0.27094 & 0.00113 \\
\hline Highly educated & 0.13846 & 0.18160 & 0.17361 & 0.36930 & 0.00016 \\
\hline Elderly & 0.05324 & 0.08367 & 0.07545 & 0.14636 & 0.00539 \\
\hline Unemployment & 0.01901 & 0.02758 & 0.02286 & 0.03876 & 0.00017 \\
\hline
\end{tabular}

factors affecting the residential heterogeneity in Hangzhou. The floating population (0.52312), the female population (0.48744), the highly educated population (0.36930), and the commercial service population (0.27094) are close to each other in the exposure dimension, and there is a certain degree of residential segregation. Finally, the unemployment group (0.03876), the agriculture-related group (0.12330), and the elderly group (0.14636) in the exposure dimension of the isolation are smaller, and the probability of contact with other groups is larger (see Table 1 and Figure 3).

In order to test the statistical significance of results, we generated a prefitted segregation class and used the distribution of these measures under the null hypothesis where segregation does not hold. As shown in Figure 4, this class was plotted to inspect the generated distribution with the estimated value from the sample (vertical red line). It is possible to see that clearly the result of $\mathrm{P}_{\text {_value }}$ is almost 0.00 , which suggests that these groups in Hangzhou city is statistically segregated at $5 \%$ of significance level ( $p$ value $<5 \%)$ in terms of $H$ and $x P x$.

4.2. Residential Heterogeneity in Different Periods and Scales. Residential heterogeneity in different geographical scales presents different spatial patterns and mechanisms, and it is difficult to explain the social spatial heterogeneity pattern of the whole city by analyzing only in single scalar or time perspective. In recent years, with the sharp rise in housing prices and the increasing importance of housing in the wealth of urban residents, residential differentiation has intensified social differentiation through such spatial differences as educational opportunities, commuting costs, and social distance [55]. Families of different classes choose different residents and its neighborhood according to their economic conditions and preferences. While low-cost housing is often accompanied by a lack of educational resources, employment opportunities, and public facilities, which aggravate the isolation from the surrounding social environment. Housing price is considered as the marketization projection of the unbalanced distribution and different demands, which makes up for the time delay and static shortcomings of the traditional studies on residential heterogeneity based on a single scale and time perspective. Therefore, based on the full-sample housing price transaction database of 6,536 residential districts in Hangzhou from
2008 to 2018, this paper further explores the scale effect and dynamic characteristics of residential heterogeneity. Firstly, we use the kernel density analysis to simulate the spatial distribution of housing price in different periods in Hangzhou. The results show that the social spatial distribution of Hangzhou is obviously uneven and fragmented, the spatial distribution pattern has changed from the West Lake-centered to Qiantang River-centered, and the residential heterogeneity in different periods shows different spatial distribution characteristics (see Figure 5).

Different from the study of housing price volatility, the study of residential heterogeneity pays more attention to the spatial justice and social mechanism behind housing price. Therefore, we estimate the number of different housing price groups by housing price and housing size and divide them into 5 groups through Jenks Nature breaks method. From the perspective of time, the dynamic characteristics of residential heterogeneity in Hangzhou show an inverted U-shaped trend, which can be roughly divided into four stages (see Table 2). In the first phase (2008-2011), the average house price in Hangzhou rose rapidly from 13,000 yuan to 20,000 yuan, while the government launched the longest-term and most stringent housing purchase restriction policy. In the second phase (2012-2014), the average housing price growth in Hangzhou slowed down and even dropped to 18,000 yuan, and the effect of the policy on the housing market began to appear. In the third phase (2015-2017), the market depression led the government to start to lift the purchase restriction and loan policy to stimulate the market, and the average housing price in Hangzhou rose to 26,000 yuan. In the fourth phase (since 2018), the average house price in Hangzhou rose to 32,000 yuan, and government departments issued a series of regulation and control policies again.

In order to explore the scale effect of residential heterogeneity, we constructed the spatial information entropy profile from 0 to 5000 meters, which is consistent with the basic rule proposed by Reardon that the larger the scale, the smaller the degree of segregation. The heterogeneity based on housing prices is more significant than that based on censuses data, and the problem of evenness is more serious than that of exposure. At the census level, evenness (0.395) and exposure (0.348) are the smallest, and the slope with scale decay was the smallest. It shows that the residential heterogeneity of different housing price groups seems not 


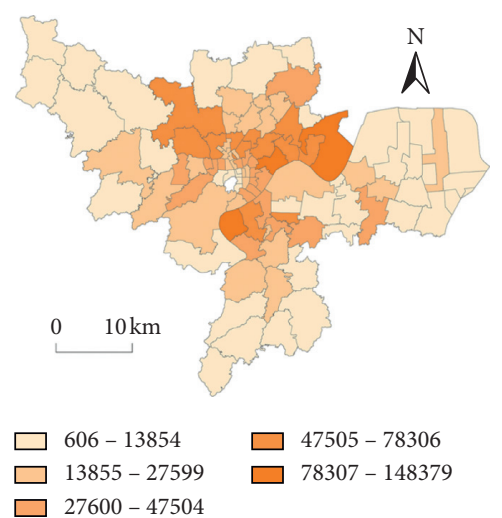

(a)

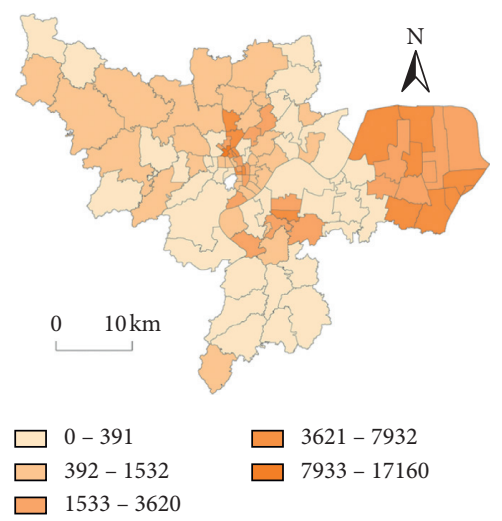

(d)

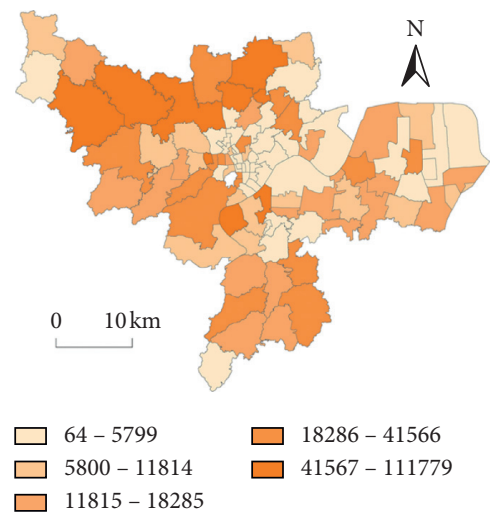

(g)
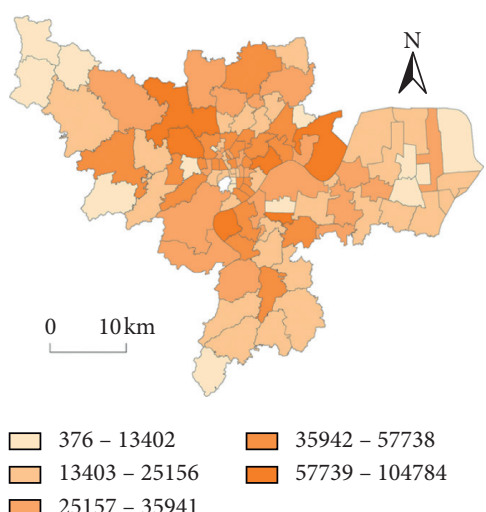

(b)
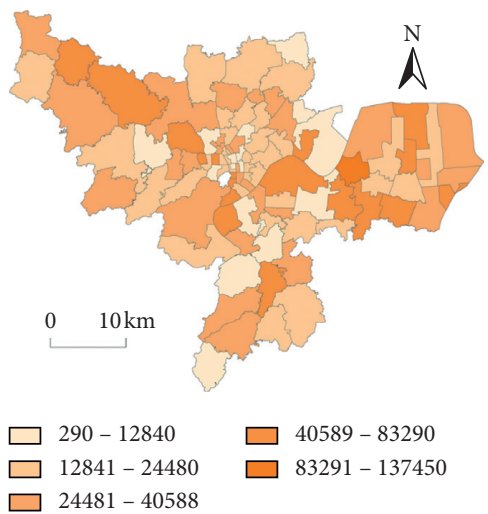

(e)

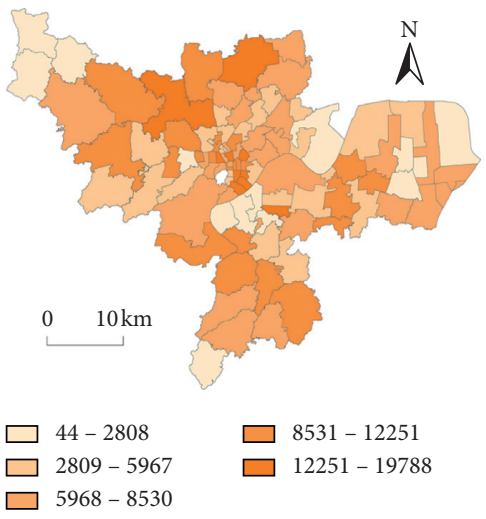

(h)

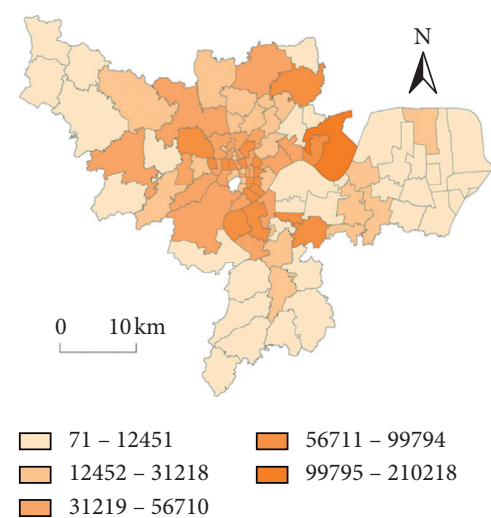

(c)

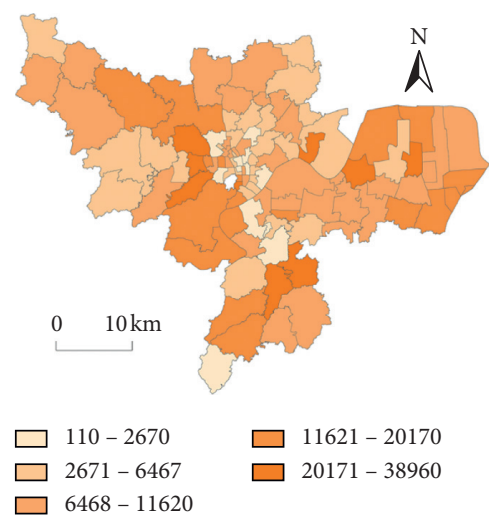

(f)

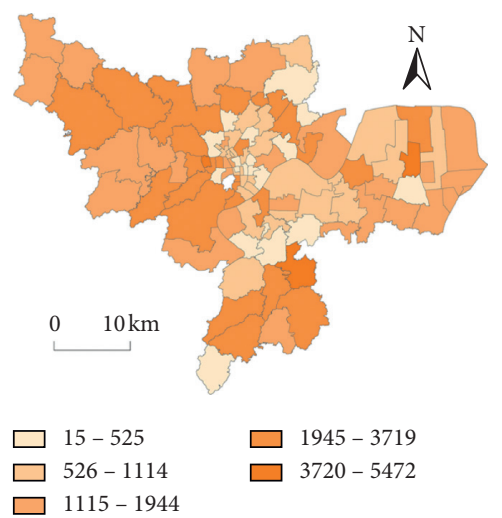

(i)

Figure 3: The distribution of different group in Hangzhou based on census data. (a) Migrant. (b) Female. (c) Hukou. (d) Agriculture and husbandry. (e) Professional and technical. (f) Business and services. (g) Highly educated. (h) Elderly. (i) Unemployment.

that significant at the macroscale, which is difficult to reflect the real situation. At the block level, the evenness (0.549) and exposure (0.490) are moderate, and the slope with scale decay is also moderate. It shows that the residential heterogeneity of different housing price groups is more significant at the mesoscale, which took neighbourhood effect into account and better reflected the real situation. At the grid level, the evenness (0.601) and exposure (0.540) are higher and closer to the results at the block scale. It shows that using grid as the basic unit may magnify the residential heterogeneity excessively, which may bring uncertainty in the comparative study of different cities (see Figure 6). The slope of the distance attenuation is most obvious within the $2000 \mathrm{~m}$ bandwidth, which is similar to the scale of a neighborhood.

With the simultaneous advancement of outward expansion and interior potential-tapping urbanization, the differentiation of residential space has gradually changed from privilege-led to territory-based. The adoption of multidimensional and multilevel housing policies or regional programs has become an effective way to reshape the space. Based on the conclusions above, we propose the 


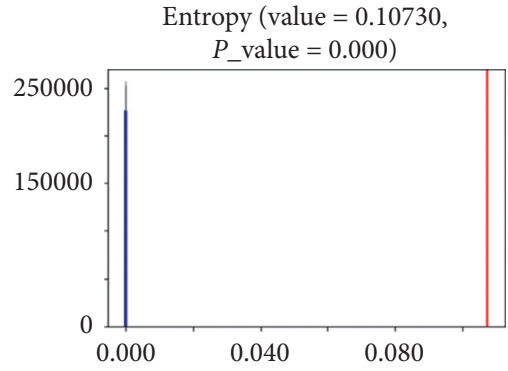

(a)

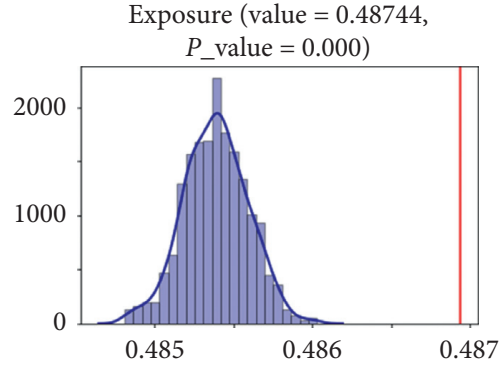

(d)

Entropy (value $=0.18064$, $P$ _value $=0.000)$

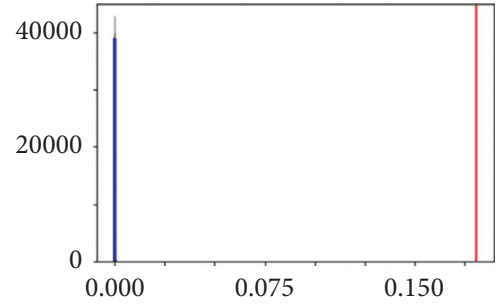

(g)

Exposure (value $=0.71963$, $P \_$value $\left.=0.000\right)$

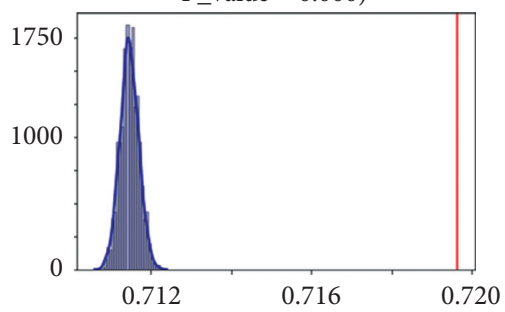

(j)

Entropy (value $=0.13846$, $\left.P_{\text {_value }}=0.000\right)$

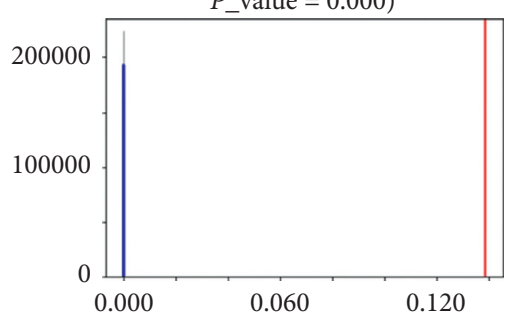

(m)

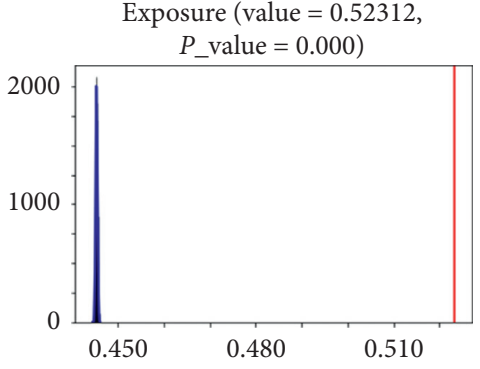

(b)

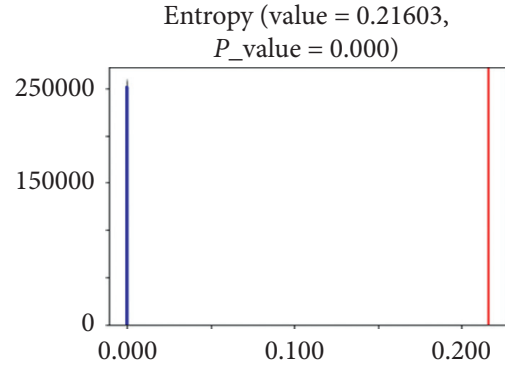

(e)

Exposure $($ value $=0.12330$, $P \_$value $\left.=0.000\right)$

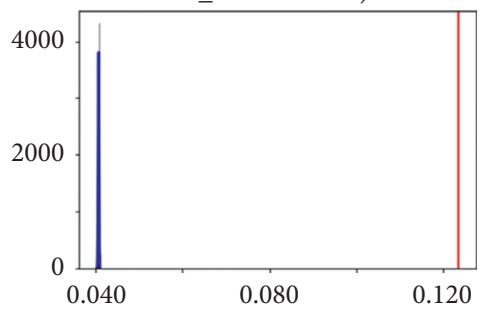

(h)

Entropy (value $=0.02711$, $P \_$value $\left.=0.000\right)$

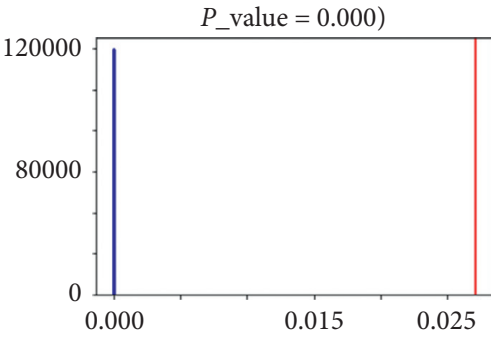

(k)

Exposure (value $=0.36930$, $P \_$value $\left.=0.000\right)$

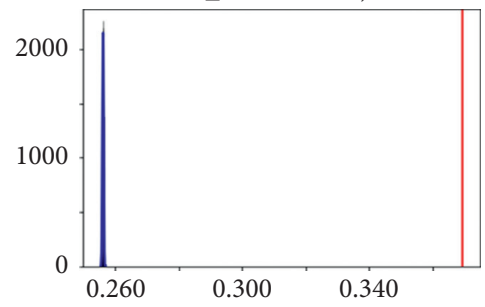

(n)

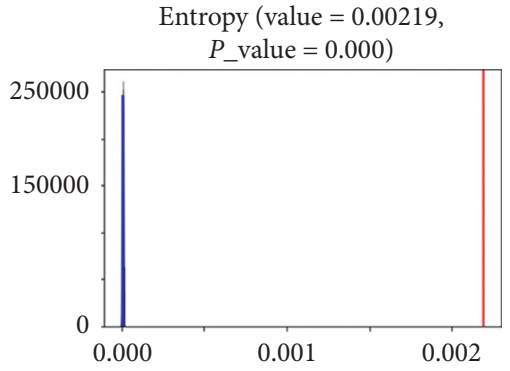

(c)

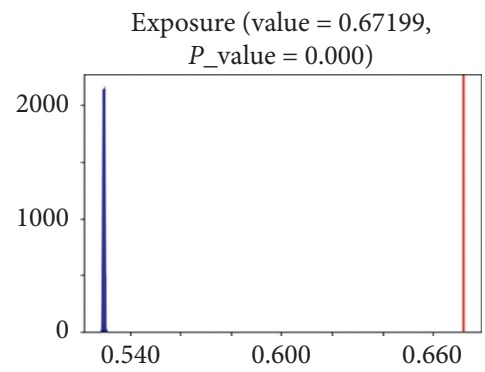

(f)

Entropy (value $=0.02431$, $\left.P_{\text {_value }}=0.000\right)$

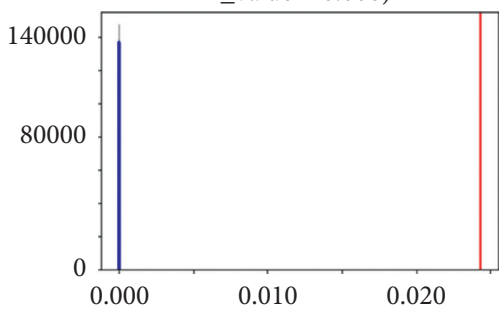

(i)

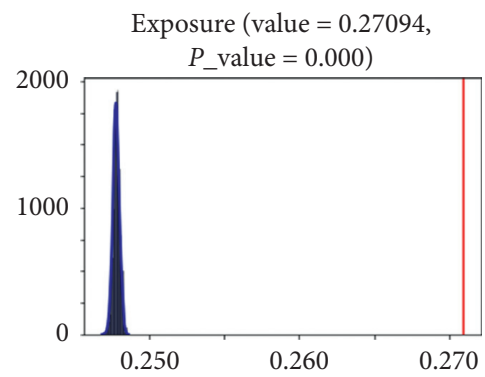

(1)

Entropy (value $=0.05324$, $P_{-}$value $\left.=0.000\right)$

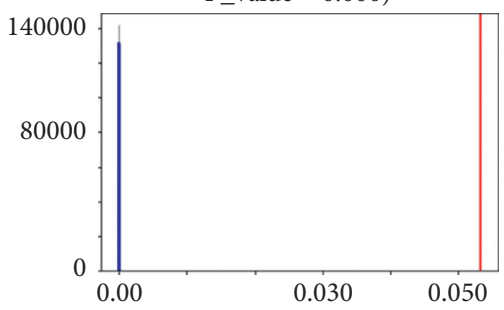

(o)

FIgURE 4: Continued. 


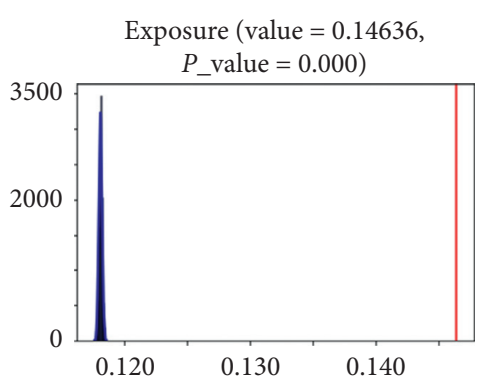

(p)

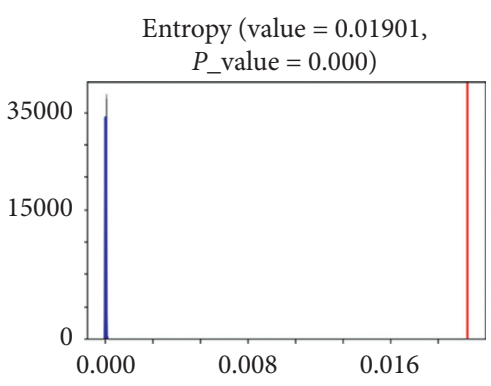

(q)

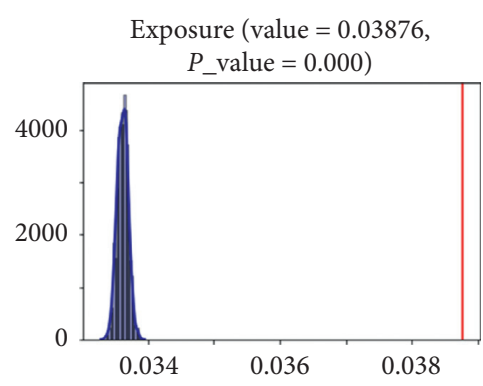

$(\mathrm{r})$

FIgURe 4: The statistical inference of information entropy in Hangzhou based on Census data. (a) Migrant H. (b) Migrant xPx. (c) Female H. (d) Female xPx. (e) Hukou H. (f) Hukou xPx. (g) Agriculture and husbandry H. (h) Agriculture and husbandry xPx. (i) Professional and technical H. (j) Professional and technical xPx. (k) Business and services H. (l) Business and services xPx. (m) Highly educated H. (n) Highly educated xPx. (o) Elderly H. (p) Elderly xPx. (q) Unemployment H. (r) Unemployment xPx.

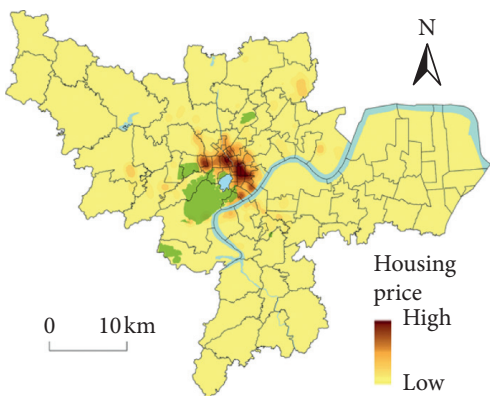

(a)

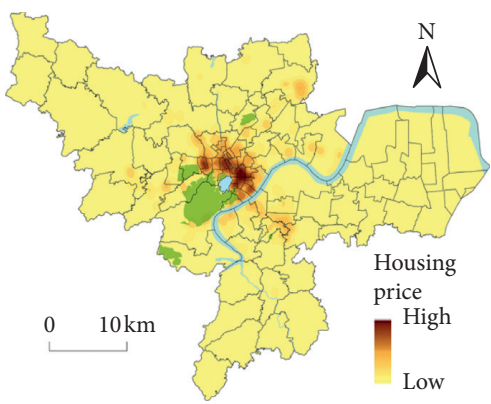

(d)

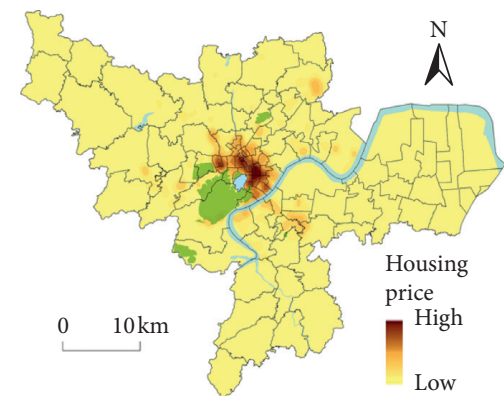

(b)

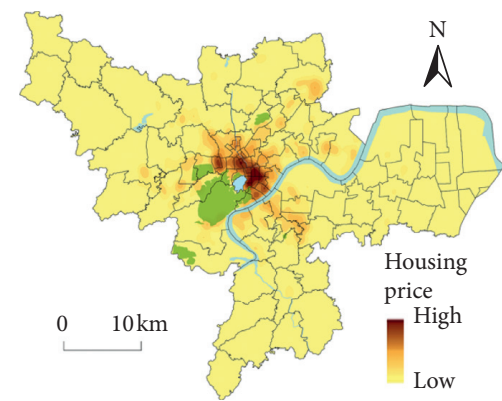

(e)

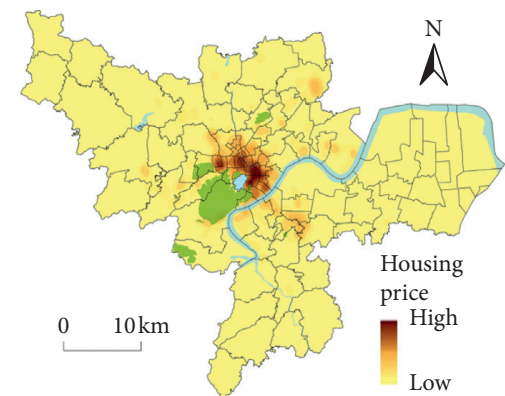

(c)

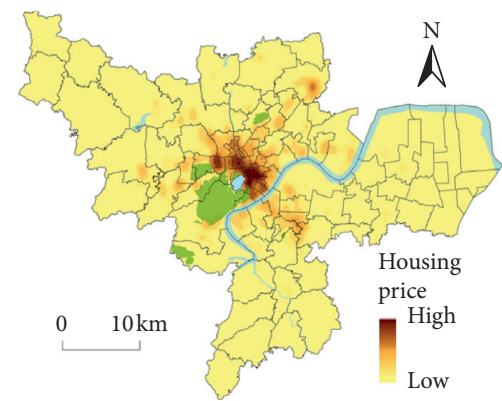

(f)

FIGURE 5: Kernel density distribution of housing price of different periods in Hangzhou. (a) 2008. (b) 2010. (c) 2012. (d) 2014. (e) 2016. (f) 2018.

TABLE 2: Residential heterogeneity of different periods and scales in Hangzhou.

\begin{tabular}{|c|c|c|c|c|c|c|c|c|c|c|c|}
\hline & 2008 & 2009 & 2010 & 2011 & 2012 & 2013 & 2014 & 2015 & 2016 & 2017 & 2018 \\
\hline Census level evenness $(\mathrm{H})$ & 0.451 & 0.422 & 0.456 & 0.492 & 0.521 & 0.581 & 0.585 & 0.531 & 0.475 & 0.424 & 0.395 \\
\hline Census level exposure (xPy) & 0.360 & 0.359 & 0.401 & 0.454 & 0.497 & 0.558 & 0.562 & 0.513 & 0.446 & 0.364 & 0.348 \\
\hline Block level evenness $(\mathrm{H})$ & 0.561 & 0.593 & 0.604 & 0.632 & 0.655 & 0.702 & 0.710 & 0.681 & 0.634 & 0.594 & 0.549 \\
\hline Block level exposure (xPy) & 0.482 & 0.542 & 0.558 & 0.596 & 0.622 & 0.673 & 0.687 & 0.657 & 0.605 & 0.531 & 0.490 \\
\hline Grid level evenness $(\mathrm{H})$ & 0.635 & 0.647 & 0.668 & 0.698 & 0.719 & 0.762 & 0.760 & 0.728 & 0.694 & 0.650 & 0.601 \\
\hline Grid level exposure (xPy) & 0.567 & 0.593 & 0.623 & 0.667 & 0.690 & 0.738 & 0.736 & 0.705 & 0.667 & 0.593 & 0.540 \\
\hline
\end{tabular}

following suggestions: from the dimension of evenness, the interaction between market regulation and government supervision is conducive to the healthy and sustainable development of residential space. Under the background of fully stimulating the market vitality and leverage of the real estate industry, a diversified housing security system should be set up to avoid the further widening of the class differentiation caused by income difference. From the dimension of exposure, providing equal public services and facilities for the relatively vulnerable groups helps to increase the communication opportunities of different groups and promote the mixed-dwelling model of different social strata. 


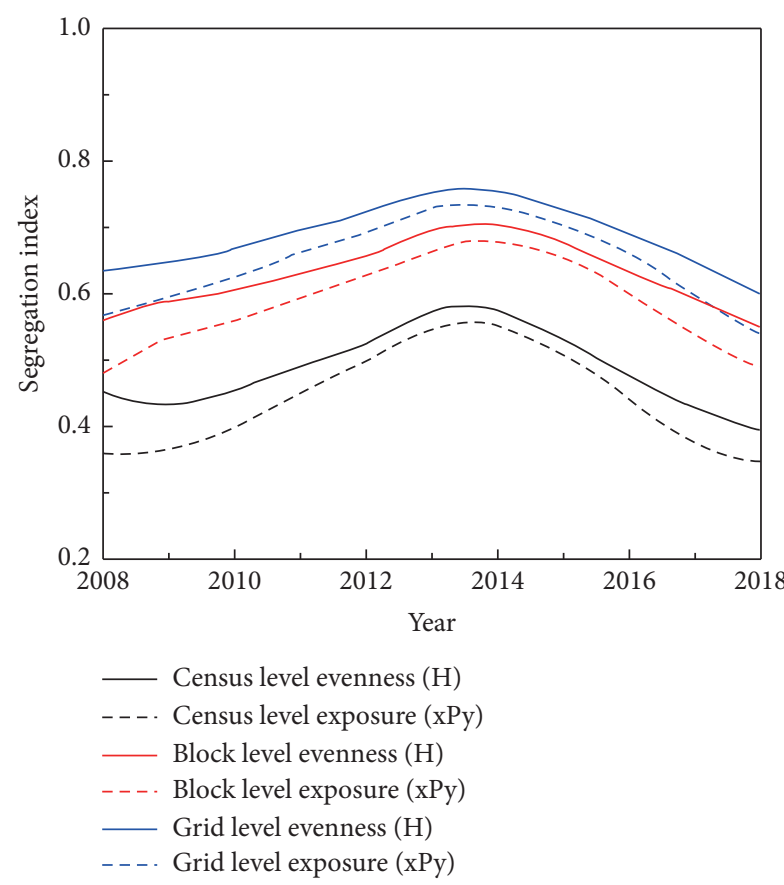

(a)

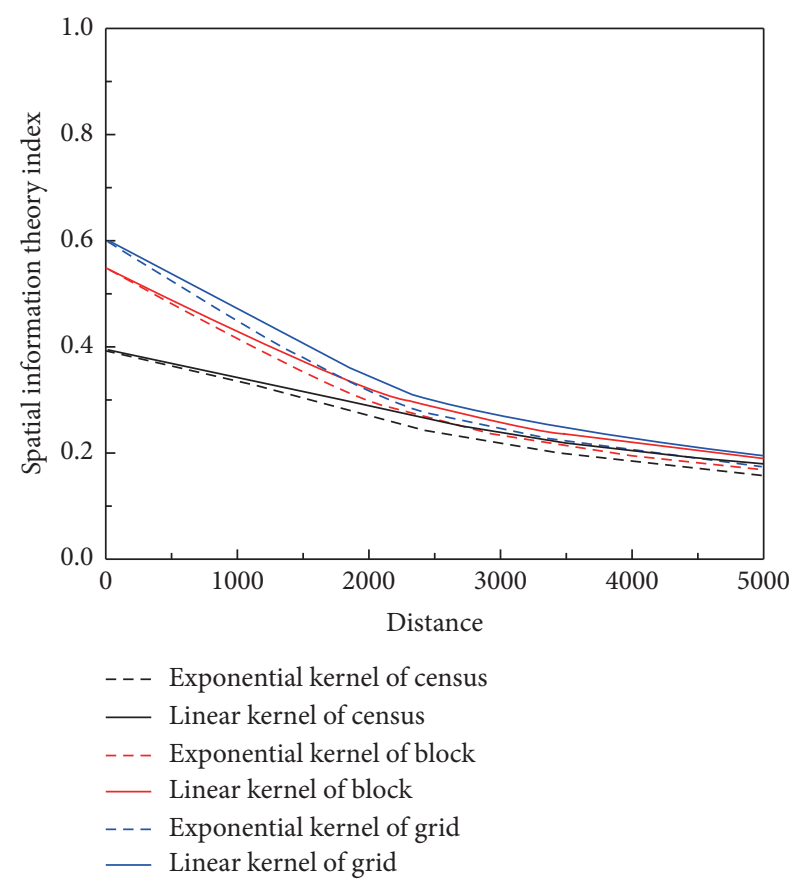

(b)

Figure 6: Residential heterogeneity of different scales in Hangzhou.

In addition, there are several limitations associated with our study. Firstly, this study is conducted based on the assumption that the housing consumption level represents the mainly social group classification, which is difficult to study the heterogeneity within the same community due to the lack of personal behavior data. Secondly, the multiscalar effects of residential heterogeneity are the comprehensive result of macro strategies and local responses, and it is difficult to consider and measure all relevant factors of residential heterogeneity. Thirdly, the data processing process of real estate speculation cannot effectively remove false information, which may have a slight impact on the results of data processing. These limitations are the direction of follow-up research.

\section{Conclusions}

Theoretically, residential heterogeneity is a complex multilevel phenomenon, which is closely related to population migration, economic transition, and historical and contemporary crises. On the one hand, it is the spatial representation of differentiation social stratum in social economy and status, and on the other hand, the result of residential heterogeneity will promote and strengthen the reproduction of social strata at the subcultural level. The multiscalar method improves the traditional approach in the following aspects: (1) In the aspect of methodological, while most of the existing research uses the nonspatial model, the multiscalar method overcomes the chalkboard and modifiable areal unit problem (MAUP) and can express the complexity and hierarchy of the social spatial structure. (2) In the aspect of dimension, while most of the existing research only discussed the dimension of evenness, this paper added exposure dimension to explain the residential heterogeneity more comprehensively. (3) In the aspect of time, while most of the existing research uses the census data, the multiscalar method overcomes the problem of time lag and described the dynamic characteristic of residential heterogeneity through the housing price group. (4) In the aspect of exactitude, traditional studies do not test the significance of the results, and the results in many empirical studies seem to be gradually decreasing and not obvious when the actual segregation is still increasing, which is called the paradox of segregation.

Empirically, this study estimated residential heterogeneity and its dynamic characteristic in both nonspatial and spatial versions and reached the following conclusions: (1) The residential heterogeneity based on housing price groups is more significant than that based on census data, which makes up for the time lag and static of census data to some extent. (2) Among different groups, the Hukou factor is tended to be the most important factor that affects the residential heterogeneity of Hangzhou in decay. The social welfare tied up with the household registration system may further lead to the solidification of the social class. (3) Comparing the three basic statistic units of census, block, and grid, the rapid expansion and the suburbanization make the global segregation at macrolevel seem less significant, while the local segregation at microlevel is still serious. And the block units enclosed by the main roads better present the neighborhood characteristics of the residential heterogeneity, which is considered to be the finest scale to analyze the residential heterogeneity. (4) From different periods throughout 2008 to 2018, although the government's 
regulation policy does not change the momentum of housing price rise in the short term, it has a long-term positive effect on alleviating residential heterogeneity in Hangzhou. Overall, the modified multiscalar approach is one of the new models and techniques for urban geographical system, which can better explain the real differentiation pattern than the traditional method.

\section{Data Availability}

Data for this work are available from the corresponding author upon request.

\section{Conflicts of Interest}

The authors declare that there are no conflicts of interest regarding the publication of this paper.

\section{Acknowledgments}

This work was supported by the Social Science Foundation of Zhejiang Province (20NDQN306YB); the National Natural Science Foundation of China (41771184, 41901196); the Key Foundation of National Social Sciences of China (17ASH003); and the Key Foundation of Education Department Hunan Province (18A001).

\section{References}

[1] D. A. Quattrochi and M. F. Goodchild, Scale in Remote Sensing and GIS, Lewis Publishers, Boca Raton, FL, USA, 1997.

[2] R. Howitt, "Scale as relation: musical metaphors of geographical scale,” Area, vol. 30, no. 1, pp. 49-58, 1998.

[3] R. Johnston, D. Gregory, and D. Smith, The Dictionary of Human Geography, Blackwell, Oxford, UK, 1994.

[4] A. Moore, "Rethinking scale as a geographical category: from analysis to practice," Progress in Human Geography, vol. 32, no. 2, pp. 203-225, 2008.

[5] K. Cox and A. Mair, "Levels of abstraction in locality studies," Antipode, vol. 21, no. 2, pp. 121-132, 1989.

[6] N. Brenner, "The limits to scale? Methodological reflections on scalar structuration," Progress in Human Geography, vol. 25, no. 4, pp. 591-614, 2001.

[7] H. Lefebvre, The Production of Space, Blackwell, Oxford, UK, 1991.

[8] R. E. Park and E. W. Burgess, The City: Suggestions for Investigation of Human Behavior in the Urban Environment, University of Chicago Press, Chicago, IL, USA, 1925.

[9] R. Harris and R. Johnston, "Measuring and modelling segregation-new concepts, new methods and new data," Environment and Planning B: Urban Analytics and City Science, vol. 45, no. 6, pp. 999-1002, 2018.

[10] S. Wickramasinghe, O. Onyerikwu, J. Sun, and D. BenAvraham, "Modeling spatial social complex networks for dynamical processes," Complexity, vol. 2018, Article ID 1472957, 12 pages, 2018.

[11] P. Batey and P. Brown, "The spatial targeting of urban policy initiatives: a geodemographic assessment tool," Environment and Planning A: Economy and Space, vol. 39, no. 11, pp. 2774-2793, 2016.

[12] G. Catney, "The complex geographies of ethnic residential segregation: using spatial and local measures to explore scale- dependency and spatial relationships," Transactions of the Institute of British Geographers, vol. 43, no. 1, pp. 137-152, 2018.

[13] P. L. Knox and S. Pinch, Urban Social Geography: An Introduction, Pearson, London, UK, 1987.

[14] D. S. Massey and N. A. Denton, "The dimensions of residential segregation," Social Forces, vol. 67, no. 2, pp. 281-315, 1988.

[15] O. D. Duncan and B. Duncan, "A methodological analysis of segregation indexes," American Sociological Review, vol. 20, no. 2, p. 210, 1955.

[16] R. Dorfman, "A formula for the gini coefficient," The Review of Economics and Statistics, vol. 61, no. 1, pp. 146-149, 1979.

[17] A. B. Atkinson, "On the measurement of inequality," Journal of Economic Theory, vol. 2, no. 3, pp. 244-263, 1970.

[18] H. Theil and A. J. Finizza, "A note on the measurement of racial integration of schools by means of informational concepts $\dagger$," The Journal of Mathematical Sociology, vol. 1, no. 2, pp. 187-193, 1971.

[19] M. J. White, "The measurement of spatial segregation," American Journal of Sociology, vol. 88, no. 5, pp. 1008-1018, 1983.

[20] B. S. Morgan, "A distance-decay based interaction index to measure residential segregation," Area, vol. 15, no. 3, pp. 211-217, 1983.

[21] C. Peach, "Good segregation, bad segregation," Planning Perspectives, vol. 11, no. 4, pp. 379-398, 1996.

[22] S. Arbaci, Paradoxes of Segregation: Housing Systems, Welfare Regimes and Ethnic Residential Change in Southern European Cities, John Wiley \& Sons, Hoboken, NJ, USA, 2019.

[23] D. J. Krupka, "Are big cities more segregated? Neighbourhood scale and the measurement of segregation," Urban Studies, vol. 44, no. 1, pp. 187-197, 2007.

[24] R. L. Morrill, "On the measure of geographic segregation," Geography Research Forum, vol. 11, pp. 25-36, 1991.

[25] D. W. S. Wong, "Spatial dependency of segregation indices," Canadian Geographer/Le Géographe Canadien, vol. 41, no. 2, pp. 128-136, 1997.

[26] D. T. Lichter, D. Parisi, and M. C. Taquino, "Toward a new macro-segregation? Decomposing segregation within and between metropolitan cities and suburbs," American Sociological Review, vol. 80, no. 4, pp. 843-873, 2015.

[27] D. W. Harvey, "Pattern, process, and the scale problem in geographical research," Transactions of the Institute of British Geographers, vol. 45, no. 45, pp. 71-78, 1968.

[28] J. Bird, "Scale in regional study: illustrated by brief comparisons between the western peninsulas of England and France," Geography, vol. 41, no. 1, pp. 25-38, 1956.

[29] S. Openshaw, "A geographical solution to scale and aggregation problems in region-building, partitioning and spatial modelling," Transactions of the Institute of British Geographers, vol. 2, no. 4, pp. 459-472, 1977.

[30] R. Johnston and K. Jones, "A classic that wasn't: statistical Geography and paths only later taken," Progress in Human Geography, vol. 44, no. 2, pp. 357-373, 2019.

[31] D. W. S. Wong, "Spatial indices of segregation," Urban Studies, vol. 30, no. 3, pp. 559-572, 1993.

[32] S. F. Reardon, S. A. Matthews, D. O. Sullivan et al., "The geographic scale of metropolitan racial segregation," Demography, vol. 45, no. 3, pp. 489-514, 2008.

[33] D. O'Sullivan and D. W. S. Wong, "A surface-based approach to measuring spatial segregation," Geographical Analysis, vol. 39, no. 2, pp. 147-168, 2007. 
[34] C. S. Fowler, "Key assumptions in multiscale segregation measures: how zoning and strength of spatial association condition outcomes," Environment and Planning B: Urban Analytics and City Science, vol. 45, no. 6, pp. 1055-1072, 2017.

[35] D. Manley, R. Johnston, K. Jones, and D. Owen, "Macro-, meso- and Microscale segregation: modeling changing ethnic residential patterns in Auckland, New Zealand, 2001-2013," Annals of the Association of American Geographers, vol. 105, no. 5, pp. 951-967, 2015.

[36] R. Johnston, K. Jones, D. Manley, and D. Owen, “Macro-scale stability with micro-scale diversity: modelling changing ethnic minority residential segregation - london 2001-2011," Transactions of the Institute of British Geographers, vol. 41, no. 4, pp. 389-402, 2016.

[37] P. Hennerdal and M. M. Nielsen, "A multiscalar approach for identifying clusters and segregation patterns that avoids the modifiable areal unit problem," Annals of the American Association of Geographers, vol. 107, no. 3, pp. 555-574, 2017.

[38] J. P. Jones, H. Leitner, S. A. Marston, and E. Sheppard, "Neil smith's scale," Antipode, vol. 49, no. S1, pp. 138-152, 2017.

[39] G. MacLeod and M. Goodwin, "Reconstructing an urban and regional political economy: on the state, politics, scale, and explanation," Political Geography, vol. 18, no. 6, pp. 697-730, 1999.

[40] R. Keil, "Extended urbanization, "disjunct fragments" and global suburbanisms," Environment and Planning D: Society and Space, vol. 36, no. 3, pp. 494-511, 2018.

[41] N. Smith, "Spaces of vulnerability," Critique of Anthropology, vol. 16, no. 1, pp. 63-77, 1996.

[42] N. Smith and W. Dennis, "The restructuring of geographical scale: coalescence and fragmentation of the northern core region," Economic Geography, vol. 63, no. 2, pp. 159-182, 1987.

[43] E. Sheppard, "The spaces and times of globalization: place, scale, networks, and positionality," Economic Geography, vol. 78, no. 3, pp. 307-330, 2009.

[44] D. Harvey, "The spatial fix-hegel, von thunen, and marx," Antipode, vol. 13, no. 3, pp. 1-12, 1981.

[45] S. F. Reardon and D. O'Sullivan, “3. Measures of spatial segregation," Sociological Methodology, vol. 34, no. 1, pp. 121-162, 2004.

[46] D. R. James and K. E. Taeuber, "Measures of segregation," Sociological Methodology, vol. 15, no. 4, pp. 1-32, 1985.

[47] Q. Huang, X. Zhu, C. Liu, W. Wu, F. Liu, and X. Zhang, "Spatial-temporal evolution and determinants of the belt and road initiative: a maximum entropy gravity model approach," Chinese Geographical Science, vol. 30, no. 5, pp. 839-854, 2020.

[48] S. Y. Hong, D. O’Sullivan, and Y. Sadahiro, "Implementing spatial segregation measures in R," PloS One, vol. 9, no. 11, Article ID e113767, 2014.

[49] P. Apparicio, J. C. Martori, A. L. Pearson, É. Fournier, and D. Apparicio, "An open-source software for calculating indices of urban residential segregation," Social Science Computer Review, vol. 32, no. 1, pp. 117-128, 2014.

[50] R. X. Cortes, S. Rey, E. Knaap, and L. J. Wolf, “An open-source framework for non-spatial and spatial segregation measures: the PySAL segregation module," Journal of Computational Social Science, vol. 3, no. 1, pp. 135-166, 2020.

[51] W. Song and Q. Wu, "Gentrification and residential differentiation in nanjing, China," Chinese Geographical Science, vol. 20, no. 6, pp. 568-576, 2010.
[52] W. X. Song and C. H. Liu, "Spatial differentiation of gated communities in Nanjing," International Journal of Urban Sciences, vol. 21, no. 11, pp. 1-14, 2017.

[53] C. X. Li, X. Gao, B. J. He, J. Wu, and K. Wu, "Coupling coordination relationships between urban-industrial land use efficiency and accessibility of highway networks: evidence from Beijing-Tianjin-Hebei urban agglomeration, China," Sustainability, vol. 11, no. 5, p. 1446, 2019.

[54] C. X. Li, X. Gao, J. Y. Wu, and K. Wu, "Demand prediction and regulation zoning of urban-industrial land: evidence from Beijing-Tianjin-Hebei urban agglomeration, China," Environmental Monitoring and Assessment, vol. 191, no. 7, p. 412, 2019.

[55] C. H. Liu and W. X. Song, "Perspectives of socio-spatial differentiation from soaring housing prices: a case study in nanjing, China," Sustainability, vol. 11, no. 9, p. 2627, 2019. 